\title{
Cynthia Harvey, Portrait du romancier en Bouddha. Balzac, Flaubert, Zola
}

\section{Maria Emanuela Raffi}

\section{(2) OpenEdition}

1 Journals

\section{Edizione digitale}

URL: https://journals.openedition.org/studifrancesi/21546

DOI: 10.4000/studifrancesi.21546

ISSN: 2421-5856

\section{Editore}

Rosenberg \& Sellier

\section{Edizione cartacea}

Data di pubblicazione: 1 décembre 2019

Paginazione: 598

ISSN: 0039-2944

\section{Notizia bibliografica digitale}

Maria Emanuela Raffi, «Cynthia Harvey, Portrait du romancier en Bouddha. Balzac, Flaubert, Zola», Studi Francesi [Online], 189 (LXIII | III) | 2019, online dal 01 mars 2020, consultato il 11 novembre 2021. URL: http://journals.openedition.org/studifrancesi/21546; DOI: https://doi.org/10.4000/studifrancesi. 21546

Questo documento è stato generato automaticamente il 11 novembre 2021.

\section{(c) (1)}

Studi Francesi è distribuita con Licenza Creative Commons Attribuzione - Non commerciale - Non opere derivate 4.0 Internazionale. 


\title{
Cynthia Harvey, Portrait du romancier en Bouddha. Balzac, Flaubert, Zola
}

\author{
Maria Emanuela Raffi
}

\section{NOTIZIA}

Cynthia Harvey, Portrait du romancier en Bouddha. Balzac, Flaubert, Zola, Québec, Éditions Nota bene, 2019, $153 \mathrm{pp}$.

1 La conoscenza del buddismo in Francia data, secondo Cynthia Harvey, dall'Introduction à l'histoire du buddhisme indien di E. Burnouf (1844), ma la sua influenza sulla letteratura francese del XIX secolo appare piuttosto ignorata e ancora da definire. L'A. si propone quindi di mostrare tale presenza in opere significative quali La Comédie humaine, Madame Bovary e Les Rougon-Macquart, benché i testi in questione non trattino dell'Oriente, ma perché cercano di rappresentare la realtà mostrandone "précisément la vacuité: ils révèlent le monde comme une illusion», in modo molto simile a ciò che si propone la dottrina buddista. Questo legame, un po' generico nella sua formulazione, trova maggiore consistenza in un testo "metafisico" come Séraphita di Balzac, definito dallo stesso autore «la doctrine en action du Bouddha chrétien» e in parte in Louis Lambert, mentre tutta la Comédie «en plus de lier l'existence de l'humain à son milieu, [...] révèle - secondo la Harvey - la vacuité, c'est-à-dire la non-existence en soi de l'humain et du monde».

2 Per Flaubert il legame con il buddismo appare mediato dall'interesse per l'Oriente e in effetti «un Bouddha trône sur sa cheminée». Il legame che l'A. cerca di instaurare fra il buddismo e Madame Bovary appare tuttavia piuttosto impalpabile, molto centrato sull'interpretazione del suicidio di Emma inteso come presa di coscienza della natura fittizia dell'ego, alla cui costruzione la protagonista si dedica per tutto il romanzo.

3 Questa necessità di «se libérer de soi-même et faire corps avec le monde», conquista estrema per Balzac e Flaubert, è per l'A. il punto di partenza dei romanzi zoliani. La fonte per la conoscenza dell'analoga indicazione buddista sarebbe in questo caso la 
lettura di Schopenhauer, all'opera in numerosi testi dei Rougon-Macquart: «La synthèse de la vie et de la mort dans l'œuvre de Zola - afferma la Harvey - témoigne également de l'importance et de l'interdépendance entre tous les éléments qui constituent la vie, et le roman». L'interdipendenza di tutti gli elementi dell'esistenza si rafforzerebbe poi in senso positivo e messianico nei cicli successivi di Villes e Évangiles, mostrando quella che è indicata qui come l'essenza del buddismo appena scoperto dalla cultura francese: «cette littérature raconte le monde et ses conflits, mais aussi les liens qui unissent l'humain à la nature et les humains entre eux». 